\title{
Urban network
}

\author{
Dr. César Ducruet \\ Centre National de la Recherche Scientifique (CNRS) \\ cdu@parisgeo.cnrs.fr
}

Pre-final version of the entry published in Richardson D. et al. (Eds.) (2017) The

International Encyclopedia of Geography, Wiley-Blackwell \& Association of American

Geographers, https://doi.org/10.1002/9781118786352.wbieg2121

\begin{abstract}
The concept of urban network implies a certain degree of interdependency among cities that are connected by various linkages at different spatial scales. Geographers but also many other scientists have theorized the urban network, leading to a wide diversity of definitions and empirical studies. We review existing approaches through three successive steps: schools of thought across scientific disciplines; operational urban networks in relation to spatial planning; and empirical analyses of intercity transport and other systems. The scarcity of studies offering a multilayered approach to urban networks and/or integrating local socioeconomic determinants motivates further research in this field.
\end{abstract}

From a historical perspective, urban networks can be seen as a particular form of organization transcending political boundaries due to their cultural and economic nature. Among the most cited examples are the Italian city-states ( $9^{\text {th }}$ to $15^{\text {th }}$ centuries), the Hanseatic League $\left(14^{\text {th }}\right.$ to $17^{\text {th }}$ centuries) in North Europe, and the Asian port cities connected by the Chinese diaspora among other vectors of exchanges (Gipouloux, 2011). Such urban networks emerged both in opposition and complement to centralized political governments in order to ensure trade and shipping activities led by merchants seeking a degree of freedom.

Numerous references to these textbook examples are found in contemporary spatial planning initiatives, such as the Randstad Holland in the Netherlands. Here and elsewhere in Europe, numerous inter-city partnerships emerged, generally aiming to value a common set of interests from local governments, partly derived from their common regional identity.

Bottom-up examples include the Nordregio project (Baltic sea region), the Bothnian Arc, the Conference of Peripheral Port Cities, the cultural network of Eurocities, or alliances among provinces rather than cities, such as the Atlantic Arc, the Mediterranean Arc, and the Channel Arc, which are other types of cross-border cooperation. The aforementioned urban networks are closely linked with European planning policies promoting a better regional balance, such as the Nordregio project being in fact part of the Interreg IIc programme. All projects have in common to be a lever for socio-economic development, based on the idea that single cities especially the small and medium-sized ones - are difficult to compete in a world dominated by so-called "global cities" and should think beyond their individualistic management. 
A more top-down example is the case of France, where under the national planning policy, a total of 24 urban networks were created between 1989 and 2000, including no less than 107 local governments, principally as a counterforce to the centralization exerted by the Greater Paris region over the entire territory. Another example but more endogenous is the South Coast Metropole Partnership in UK, promoting a functional region in the 'shadow' of Greater London. This central southern region animated by its main urban centers was seen by its proponents as a more relevant planning unit than the traditional Southeast and Southwest administrative regions, which lacked decisional power. As such, urban networks constitute new institutions, conduct a common policy, in order to achieve synergy, reach a critical mass, complement their functions, and strengthen a coherent regional system, based on more or less geographic proximity (Brunet, 1996). An assessment of the success of such initiatives is difficult, given the diversity of cases, and the fact that many of them have been discontinued, often due to the changing political agenda of the concerned municipalities. Yet, some urban networking strategies proved to be efficient when focusing on a specific project rather than simply creating an "image" for potential investors, like the creation of a common university, airport, and missing motorway link, to name but a few examples.

Throughout the academic literature, the surge of studies on urban networks since the 1960s motivated scholars to summarize the field. They conclude to a dispersal of approaches and definitions, to such an extent that urban network research "does not represent a standardised and consolidated field of scholarship" as this approach varies "immensely in their research questions, scales of analysis, disciplinary perspective, and intended audiences" (Derudder and Neal, 2019). The urban network concept itself may be coined differently across the academic spectrum, from city network, city system, system of cities, urban system, but also various spatial forms such as conurbations and megalopolises. As stated by Derudder and Neal (2019), the variation among existing studies comes from three main elements: the scale of analysis adopted, the urban processes captured, and the ontological status ascribed to the network under study. The crossing between network science and urban studies made it possible to consider urban networks as graphs (cf. graph theory) where cities are nodes or vertices and their mutual connections are links or edges (Derudder, 2019). We present below the different schools of thought and their evolution.

Interestingly, the pioneering studies of urban networks were closely related to spatial planning issues. Two main poles actively researched the properties of urban networks during the 1960s and 1970s, namely an Anglophone group and a Swedish group, both adapting quantitative methods of regional science to regional planning issues. The main innovation of this "first science of cities" was to shift from intra-urban to interurban dynamics, greatly inspired by the central place theory developed by Christaller and Lösch. Brian Berry (1964)'s expression of "cities as systems within systems of cities" is emblematic of such a shift, following Edward Ullman (1954)'s horizontal definition of the urban network, which rested on three main elements: complementarity, economic opportunity, and distance. Alan Pred (1977) provided a clear definition of the urban network that is still valid nowadays: a national or regional group of interdependent cities where changes in one city (e.g. economic activities, professional structure, wages or population) will affect the other cities. Based on such a relatively unified conceptual framework, geographers and regional scientists proposed numerous analysis of urban networks using various flow matrices, but mainly using urban population as the key variable to test the rank-size rule (or Zipf law) governing urban networks in both developing and developed countries, for instance to demonstrate their degree 
of centralization (primacy) or integration. Other studies looked at the diffusion of innovations across urban networks, with reference to the pioneering works of Hägerstrand (1953), mostly concluding to hierarchical tendencies whereby larger cities are first adopters before redistribution to smaller cities. The Swedish school was particularly keen in establishing direct links between national planning problems and urban network theories, based on the observation that population and economic activities were too much concentrated in Sweden's main urban centers. Authors such as Godlund, Öberg, Olsson, and Törnqvist, among others, produced several reports for the central governments aiming at understanding the spatial dynamics of information flows across the urban network, contrary to Anglo-Saxon scholars focusing mainly on physical flows and infrastructures (Peris, 2016). Another originality of Swedish geography was to interview businessmen to produce simulation models capable of predicting future urban network patterns, with reference to the organization theory, integrating additional data on commuting flows for instance.

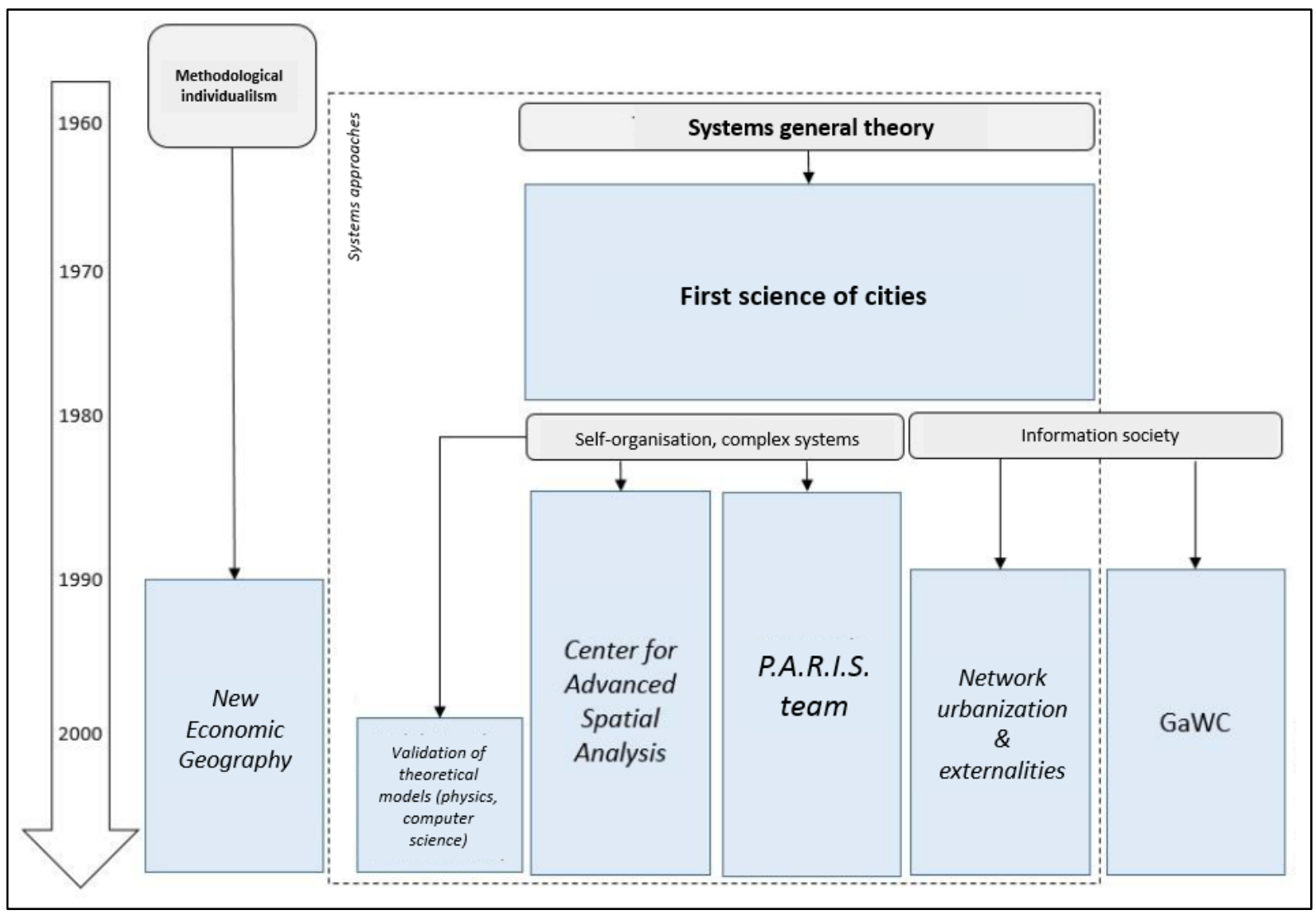

Figure 1: Evolution of schools of thought about urban networks

Source: adapted from Peris (2016)

In the following decades, research on urban networks went through a fragmentation with the emergence of separated schools of thought having their own definition and theory on the matter (Peris et al., 2018), sometimes in opposition to the aforementioned classic models. Each research domain often claimed to offer a 'new paradigm'. Yet, certain similarities can be found, especially given the growing interdisciplinary character of such researches in their use of quantitative methods such as network analysis. A French school around the geographer 
Denise Pumain emerged in the 1970s and 1980s, taking distance from classic models by referring to self-organization, synergetic, and coevolution, thereby formulating an "evolutionary theory of cities". Experiments using agent-based models and multivariate analysis were proposed, mainly looking at the distribution of urban population and transport networks across nations and continents over long time spans. Similarities can be found with what was coined the "new science of cities" promoted by Michael Batty in the United Kingdom, such as the reference to and use of biology and physics methods to describe urban networks, like scaling laws. Such laws are the statistical relationships between urban attributes and urban population across cities of a given country, which can be interpreted as expressions of the urban network's degree of centralization, especially for the most advanced activities (e.g. employment in research and development activities).

Another school emerged in the 1990s with reference to Jean Gottmann's (1961) work on the U.S. megalopolis. Improvements in transport and communication technologies, the fading role of distance, and the rise of the service economy as well as globalization motivated scholars to identify polycentric forms of urban development in various parts of the world, such as Northern Italy, the Randstad, and Kansai in Japan. The "city network paradigm" (Capello, 2000) is thus a criticism of the dominantly hierarchical conception of urban networks of the two previous schools. For such authors, cities are specialized in certain firms' activities and connect through horizontal linkages as a matter of complementarity, thereby generating positive externalities, vertical integration, cooperation, innovation, and synergy effects (Camagni and Salone, 1993). The main geographical focus of this school is at the subnational level, searching for relevant examples of urban networks or "districts" having such properties, in close relation to spatial planning issues as said above.

Economics in general, and the New Economic Geography in particular, devoted its attention to the concentration and location of various urban activities, defining the urban network as "a collection of economic agents (consumers and firms) without or with limited spatial interactions, with static, comparative, and equilibrium methods as the basic core of the analysis" (Ducruet and Lugo, 2013). Based on the principle that distance does not affect the mobility of economic agents among cities, authors included the Dixit-Stiglitz assumptions of monopolistic competition and the null trading cost in their models, providing important economic mechanisms for understanding specialized and diversified cities. The second principle is iceberg costs, i.e. the increasing fraction of product price due to mobility. Yet in this school cities are considered as nodes in a linear or circle structure, in a so-called racetrack economy where distance remains neutral as "regions are equally spaced" (Abdel-Rahman and Anas, 2004). Related methodologies and applications often used spatial interaction and gravity models, and due to issues in explaining social behavior by natural science models, adaptations were made using more realistic tools such as spatial autocorrelation and heterogeneity. One important difference with other schools is the absence of reference to the physical flow itself linking cities, as this approach to urban networks is highly theoretical.

Lastly, an important change in the way urban networks are analyzed had been to shift the focus to "world city networks", having in common with the "city network paradigm" to focus on services location and firms' networks but at the global level. Such a school takes its roots in the works of Manuel Castells on the information society describing how spaces of flows are functioning, but also from previous works of John Friedmann and Saskia Sassen on the "world city" or "global city", concluding to the existence of a transnational urban system. 
These foundations provided strong support to the geographer Peter Taylor and his Globalization and World Cities (GaWC) Study Group and Network to provide numerous empirical analyses of such systems based on company data. Based on the interlocking network model applied to advanced producer services location across cities of the world, cities are ranked and classified to unravel the global urban hierarchy of alpha, beta, and gamma centers. The link with the emerging literature on global commodity chains and global production networks motivated scholars to study other types of linkages such as airlines but also specialized services like those related to maritime transport (Jacobs et al., 2010). Peter Taylor et al. (2010) even proposed a "central flow theory" in opposition to the central place theory which remained bound to the local or national scale and ignored the relational aspects of urban networks.

As argued by Ducruet and Beauguitte (2014) and Derudder (2019), the network analysis of interconnected cities went through unprecedented change in the last two decades, following the growing integration of complex networks methods from physics into geography and other social sciences, but also the growing interest of physicists for cities and real-world networks. Far from being a school of thought per se, this methodological breakthrough, combined with increased computational power, the development of dedicated graph analysis software, and newly available data on interurban relationships permitted scholars to concretely measure and visualize the structure and dynamics of urban networks, thereby creating a dialogue or common ground among the different schools of thought. Such an approach first permitted to identify the global properties of urban networks, i.e. their resemblance to theoretical models such as the scale-free and small-world networks. It also allowed to compare cities based on their various centralities in the network (Guimera et al., 2005), and to extract, from a large network, different and strongly interconnected subsystems, to test, for instance, the existence of barrier effects such as distance or borders. Few analyses, however, tackled the difficulty to study multiple linkages at a time, or analyzed the urban network by considering the socio-economic characteristics of the connected cities. In the world maritime network of cities, since the late $19^{\text {th }}$ century, the most populated nodes remained dominant until new hubs emerged thanks to progresses in shipping and port technology as well as operational modifications, as shown per using single linkage analysis and assortativity measures (Ducruet et al., 2018). Other studies could show the connivance between urban Gross Domestic Product, population, and centrality in airline urban networks. When it comes to multiple linkages, studies often looked at the degree of overlap of at least two transport modes on nodes and on links, but without taking into account the characteristics of cities (see Ducruet et al., 2011; Derudder et al., 2014). Should it be in natural or social sciences, the complex networks approach remains usually rather static and does not consider node attributes. Thus, the future or urban network research should lean towards the analysis of a fully-fledged network where nodes and links have multiple characteristics and evolve overtime. Only then the full understanding of urban networks be possible, allowing to unravel how network diversity and dynamics affect urban growth and vice-versa.

SEE ALSO: Graph Theory; Network Analysis; Spatial Networks; Transport Networks 


\section{References and Further Readings}

Abdel-Rahman H., Anas A. (2004) Theories of systems of cities. In: Henderson J.V., Thisse J.F. (Eds.), Handbook of Regional and Urban Economics, pp. 2293-2339.

Berry B.J.L. (1964) Cities as systems within systems of cities. Papers in Regional Science, 13(1): 147-163.

Brunet R. (1996) L'Europe des réseaux. In: Pumain D. and St. Julien T. (Eds.) Urban Networks in Europe, Montrouge: John Libbey Eurotext-INED, pp. 131-150.

Camagni R.P., Salone C. (1993) Network urban structures in northern Italy: elements for a theoretical framework. Urban Studies, 30(6): 1053-1064.

Capello R. (2000) The city network paradigm: measuring urban network externalities. Urban Studies, 37(11): 1925-1945.

Derudder B. (2019) Network analysis of 'urban systems': potential, challenges, and pitfalls. Tijdschrift voor Economische en Sociale Geografie, https://doi.org/10.1111/tesg.12392

Derudder B., Liu X., Kunaka C., Roberts M. (2014) The connectivity of South Asian cities in infrastructure networks. Journal of Maps, 10(1): 47-52.

Derudder B., Neal Z. (2019) Uncovering links between urban studies and network science. Networks and Spatial Economics, 18: 441-446.

Ducruet C., Beauguitte L. (2014) Network science and spatial science: review and outcomes of a complex relationship. Networks and Spatial Economics, 14(3-4): 297-316.

Ducruet C., Cuyala S., El Hosni A. (2018) Maritime networks as systems of cities: the longterm interdependencies between global shipping flows and urban development (1890-2010). Journal of Transport Geography, 66: 340-355.

Ducruet C., Ietri D., Rozenblat C. (2011) Cities in worldwide air and sea flows: A multiple networks analysis. Cybergeo: Revue Européenne de Géographie, 528:

http://cybergeo.revues.org/23603

Ducruet C., Lugo I. (2013) Cities and transport networks in shipping and logistics research. Asian Journal of Shipping and Logistics, 29(2): 149-170.

Gipouloux F. (2011) The Asian Mediterranean: Port Cities and Trading Networks in China, Japan and Southeast Asia, 13th-21st Century. Cheltenham and Northampton, MA, Edward Elgar Publishing.

Guimera R., Mossa S., Turtschi A., Amaral L.A. (2005) The worldwide air transportation network: Anomalous centrality, community structure, and cities' global roles. Proceedings of the National Academy of Sciences USA, 102(22): 7794-7799.

Jacobs W., Ducruet C., De Langen P.W. (2010) Integrating world cities into production networks: The case of port cities. Global Networks, 10(1): 92-113.

Peris A., Meijers E., van Ham M. (2018) The evolution of the systems of cities literature since 1995: schools of thought and their interaction. Networks and Spatial Economics, 18: 533-554. 
Pred A. (1977) City Systems in Advanced Economies: Past Growth, Present Processes, and Future Development Options. Wiley.

Taylor P. J., Hoyler M., Verbruggen R. (2010) External urban relational process: introducing central flow theory to complement central place theory. Urban Studies, 47(13): 2803-2818.

Ullman E.L. (1954) Geography as spatial interaction. In: Interregional Linkages, Proceedings of the Western Committee on Regional Economic Analysis, Berkeley, pp. 63-71. 